\title{
NUMERICAL MODELS FOR FATIGUE CRACK EVOLUTION STUDY
}

\author{
Ion Fuiorea, Daniela Bartis, Roxana Nedelcu \\ Military Technical Academy, Bucuresti, Romania \\ Florin Frunzulica \\ Polytechnic University, Bucuresti, Romania
}

\begin{abstract}
The paper presents some considerations regarding to the numerical simulation of the behaviour of the riveted structures in fatigue loading conditions. In order to estimate the stress intensity factor, " $k$ ", different constitutive laws for the materials were considered. Choosing different contours for " $J$ " integral calculation, some simplified models were studied. The final numerical results were analysed with respect to the physical tests.
\end{abstract}

\section{INTRODUCTION}

The Romanian Research Authority is financing a project developing design, prototype manufacture \& test and certificate a CS23 aircraft. Inside this project STRAERO was involved with tasks consisting in design and structural test. During the preliminary technical \& economical study, our institute participates at a research task consisting in the study of the influence of the constructive and technological parameters upon the fatigue strength of the riveted connections of the structure. The main considered parameters were: the type of rivet head (round head and countersunk), the diameter of the rivet versus the connected blade thickness and the riveting force.

The present work deals with a technology proposed to be used in order to simulate the mechanism of deterioration of the riveted aircraft structures as a result of fatigue of the jointed areas. In the same time some simplified techniques are presented together with the reasons that validate them with respect to complex formulation cases as well as to the experimental ones.

\section{GENERAL PHILOSOPHY OF FATIGUE RUPTURE SIMULATION}

The behaviour of the riveted structures at variable loadings connected with fatigue phenomenon numerical simulation can be performed considering, generally, two main stages:

- in the first stage the durability of the structure is determined until the first crack apparition in the riveted joint;

- the second stage consists in the analysis of the crack evolution and "reserve of durability" is calculated step by step until the final rupture.

The method adopted for the first stage is a cumulative damage method based on the Miner's rule. According to Miner's rule, it is assumed that there is no interaction between different events, i.e. each event (consisting of a number of cycles of the same load level) occurs in complete isolation from the other events, and as a consequence, the total damage in a point is: 


$$
D=\sum_{i} \frac{n_{i}}{N_{i}}, \quad i=\overline{1, m}
$$

Where: $D$ is cumulated damage, $n_{i}$ - number of cycles at the $i^{\text {th }}$ sequence, and $N_{i}$ the ultimate number of cycles for the same sequence. The stage is considered to be finished when at least in one point of the structure $\mathrm{D}=1$. As a consequence of this rule, the first crack apparition occurs in the location(s) where $\mathrm{D}=1$.

After the final moment of first stage, when the first crack is considered to be appeared in the location where $\mathrm{D}=1$, the second stage of simulation is initiated: the crack evolution by using fracture mechanics techniques. In the same time, the values of cumulated damage are still determined for each step-time in order to identify the other points where new cracks are formed.

For fatigue durability prediction methodology, the Paris law was chosen:

$$
\frac{\mathrm{da}}{\mathrm{dN}}=\mathrm{C} \cdot \Delta \mathrm{K}^{\mathrm{n}} \Leftrightarrow \frac{\mathrm{da}}{\mathrm{dN}}=\mathrm{C} \cdot[(1-\mathrm{R}) \cdot \mathrm{K}]^{\mathrm{n}}
$$

where: da is the elementary growth of the crack, $\mathrm{dN}$ - the corresponding number of cycles, $\mathrm{C}$ and $\mathrm{n}$ are the material parameters defined by fracture mechanics, and $\mathrm{R}$ the asymmetry coefficient. As it will be presented later, the plane crack problem was considered and the two cracking modes were condensed in an equivalent stress intensity factor defined by Tanaka:

$$
\mathrm{K}_{\mathrm{eq}}=\sqrt{\mathrm{K}_{\mathrm{I}}^{2}+\mathrm{K}_{\mathrm{II}}^{2}}
$$

where: $\mathrm{K}_{1}$ and $\mathrm{K}_{2}$ are the stress intensity factors corresponding to each considered mode.

The evaluation of the stress intensity factors was performed by considering the $\mathrm{J}$ integral metod

$$
\mathrm{K}_{\mathrm{eq}}=\sqrt{\mathrm{E} \cdot \mathrm{J}}
$$

where: E is Young modulus, and $\mathrm{J}$ - the Rice integral

$$
J=\int_{1}\left(w \cdot d y-p \cdot \frac{\partial D}{\partial x} \cdot d s\right)
$$

with the tensile vector $\mathrm{p}$ and displacements vector D on the "l" contour (arbitrarily chosen).

More details on each stage technology of simulation will be presented in next chapters.

\section{3D ANALYSIS FOR THE LOCATIONS OF CRACK INITIATION}

As the experiment demonstrates the most dangerous crack evolution in the case of multiple-site damage when simultaneously or temporarily very close crack initiation takes place on a riveted structure. In this case the speed of propagation of the crack highly increases with unfavourable discontinuities when the cracks joint together.

3D numerical simulations as well as the physical experiments demonstrate, as shown in figure 1 , that the most dangerous points of the riveted structure where the stress concentration is present are those situated in the neighbourhood of the rivet holes on the interior parts of the plates.

The main observation that can be done analysing the stress state in the figure 1 is that the initiation of the crack (nucleation zones) took part at the hidden part of the plates, at the rivet hole 
border and on the contact surfaces of the plates. That fact can cover an important period of fatigue durability of the structure.

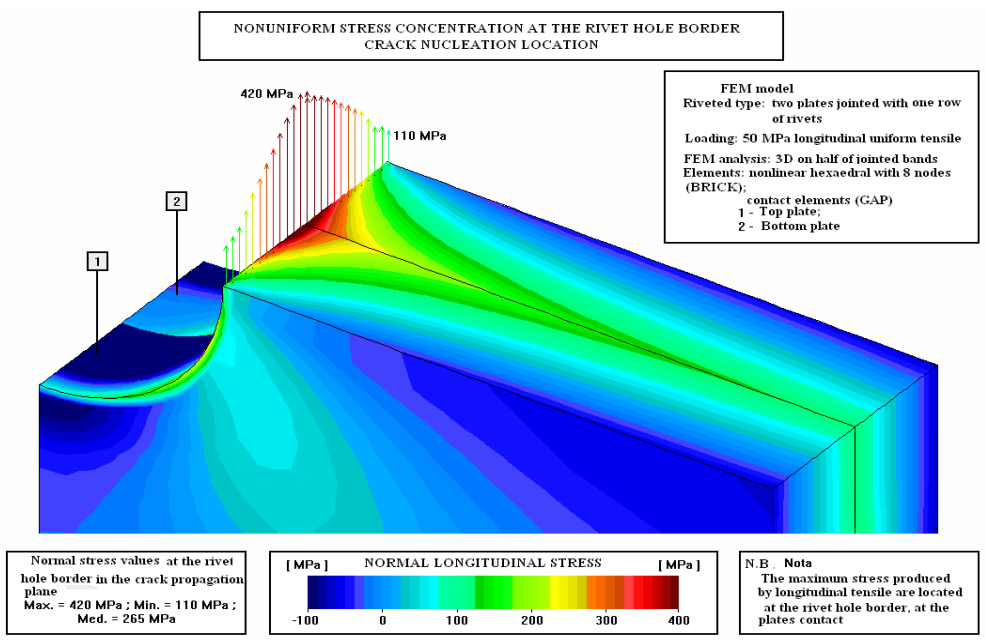

Fig. 1 Stress concentration at the border of rivet hole

\section{A QUASI - 2D FEM MODEL OF THE RIVETED PLATES}

The experience demonstrates that a 3D FEM model of the riveted plates for no more than 8 rivets requires about 1024000 nodes i.e. about 3000000 equations for one step in the nonlinear analysis. And this requires a huge calculus effort. The authors propose a simplified model for FEM analysis that reduced considerable the calculus effort and allows models for complex riveted structures.

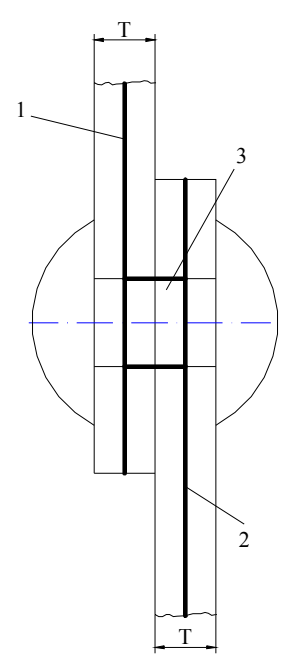

a)

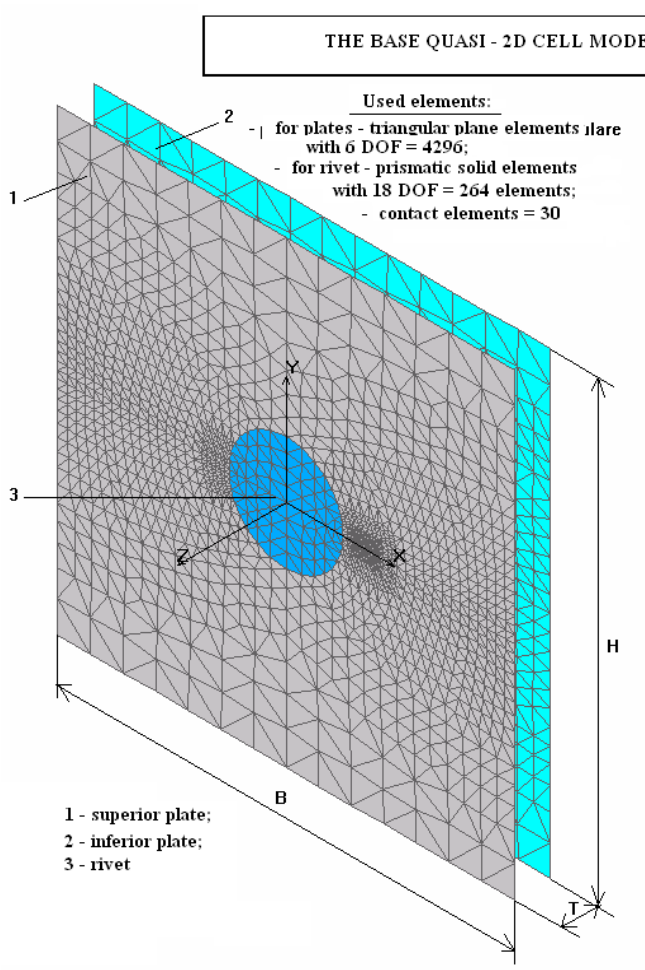

ivet lole refined mesh at the rivet hole margin with $p=0.2 \mathrm{~mm}$

b)

Fig. 2 Quasi 2D model and the basic cell 


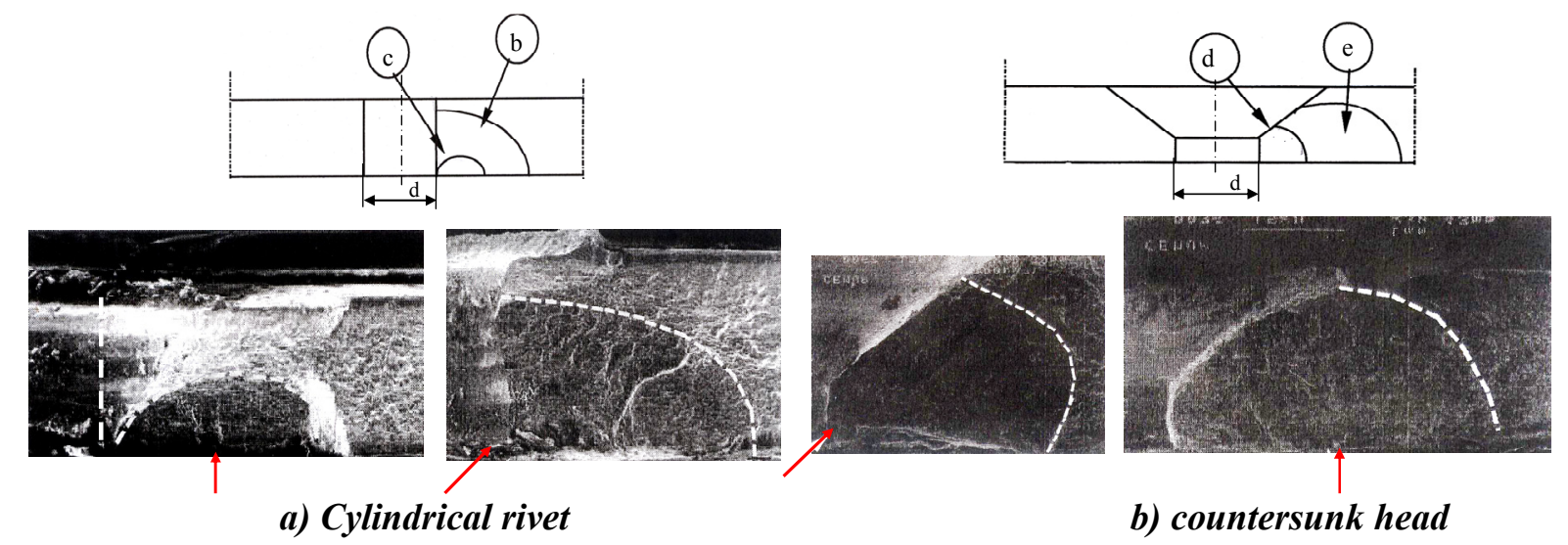

Fig. 3 The crack initiation and propagation

In Fig. 2.a) a quasi 2D FEM model is presented. It consists in the representation of the middle surfaces of the plates by using 2D PLANE elements, considering a plane problem. On contrary, the rivet will be modelled by using 3D SOLID elements. Considering the mentioned model a basic cell for riveted plates (Fig. 2.b) can be realised and multiplied as wish in order to obtain complex structures. The advantages of the model consist in:

- its simplicity connected with an economic budget of time - solving;

- as it will be presented later, a good accuracy of crack propagation simulation is obtained;

- the contact is presented only on curves.

The model presented in Fig. 2 has some limits that can be neglected or not, depending on the type of analysis, as follows:

- no bending aspects of the plates are considered;

- the stress state in the rivet is not totally according to the real case;

- the initiation of the crack is not in the middle surface as the experience illustrates (Fig. 3); that will induce an error consisting in the moment of the crack initiation. Really, in the simulation process the start moment of crack initiation will be coincident with the moment when the crack intersects the middle surface, for the real case.

\section{STRESS FIELD ANALYSIS AT THE TOP OF THE CRACK}

As mentioned at the $2^{\text {-nd }}$ chapter, the second stage of durability of riveted joints develops the study of the crack propagation, as a result of stress field at the top of the crack. The fracture mechanics reasons presented in the same chapter denotes that important steps in this stage were the stress intensity factor, $\mathrm{K}$, and $\mathrm{J}$ integral evaluation.

The alloys considered for aircraft structures have an elasto-plastic constitutive law and that implies a complex nonlinear calculus when FEM is used. In the same time a linear elastic model will induce singularities in the Irwin representing mode i.e. the stress values at the top of the crack will be infinite.

In the reason of calculus time economy, this chapter presents a comparative study of the stress intensity factor, $\mathrm{K}$, and $\mathrm{J}$ integral evaluation by using FEM for two cases of constitutive laws of materials: linear elastic and elasto-plastic laws.

In fig. 4 the FEM model is presented for the two cases of considered constitutive laws with details regarding the mesh around the crack top as well as the chosen integration contours for $J$ integral. As a detail in the figure are comparative presented the obtained values for stress intensity factor corresponding each contour and for the considered constitutive laws.

In the Fig. 5 the equivalent von Misses stress are presented. 


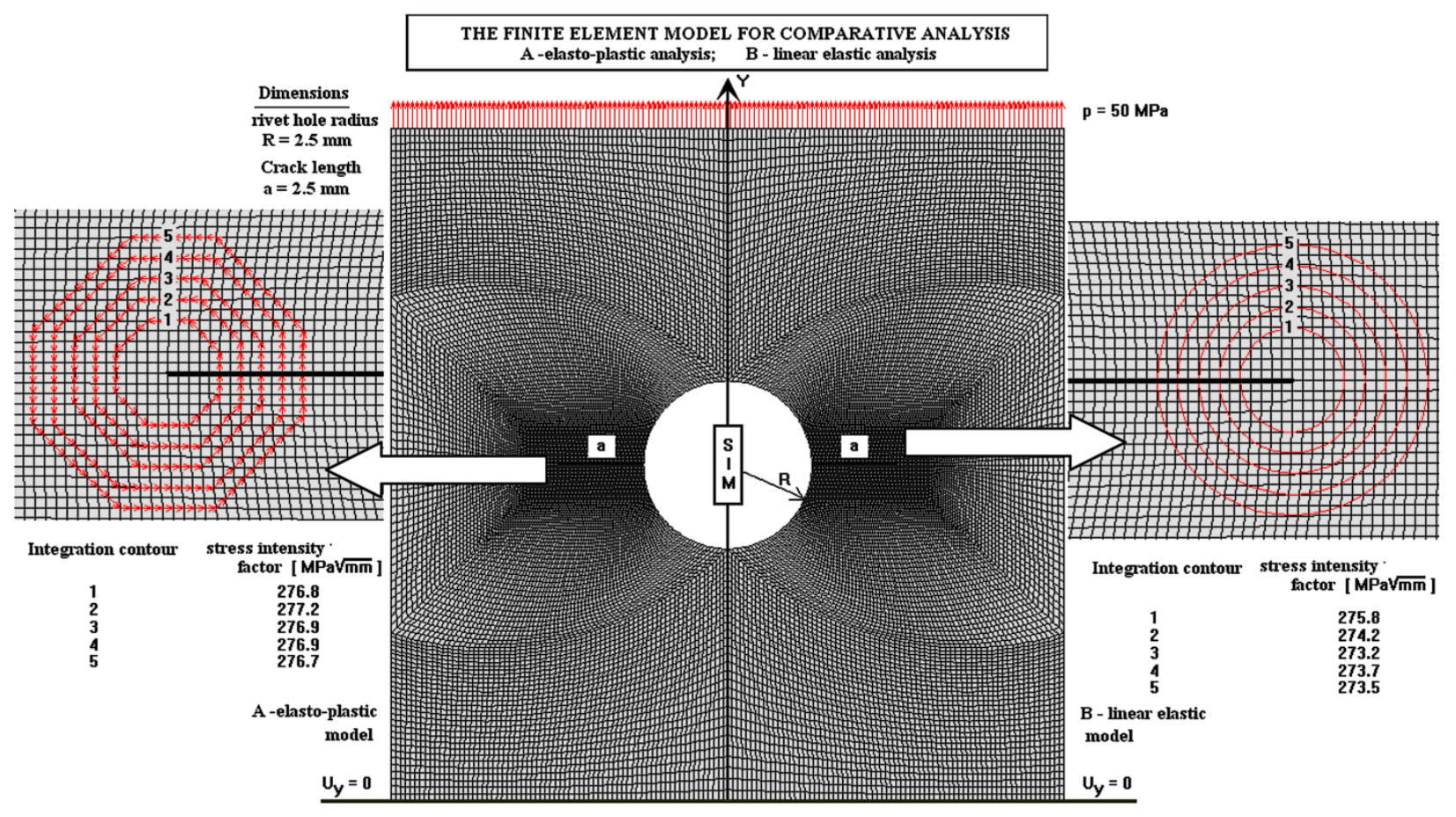

Fig. 4 FEM model for the two constitutive laws

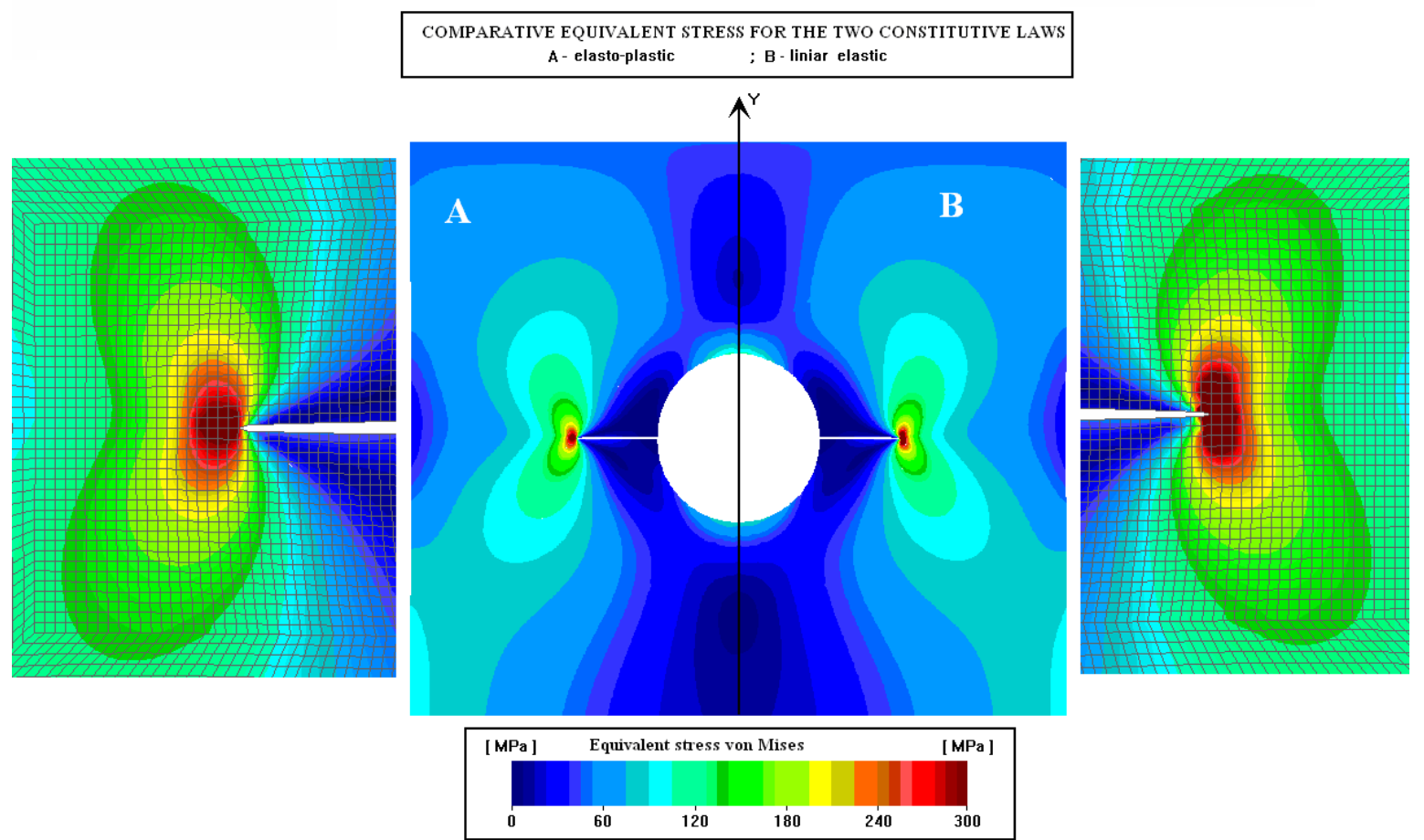

Fig. 5 Von Mises equivalent stress comparative analysis

A carefully analysis of the two maps of stress in Fig. 5 some big differences can be noticed but very near by the top of the crack, where the stress states are quite different (in the linear elastic model the stress can be as great as possible while in the elasto-plastic model the maximum value of the equivalent stress cannot be greater than the corresponding yield stress). But as the position is far and far from the top, the stress values are going to be equal. The symmetry of the representation denotes this observation. 
In the Fig. 6 a representation of the error was performed in order to estimate the contour where the stress values differences for the two considered constitutive laws are enough small to be able to use the linear elastic law. The chosen field variable, von Mises stress, is preferable taking into account that it encloses all the components of the stress tensor. On the detail in Fig. 6 two zones can be distinguished:

- a zone centred on the top of the crack (I) where the error is greater than $10 \%$;

- a zone out of the first one (II) where the error is acceptable.

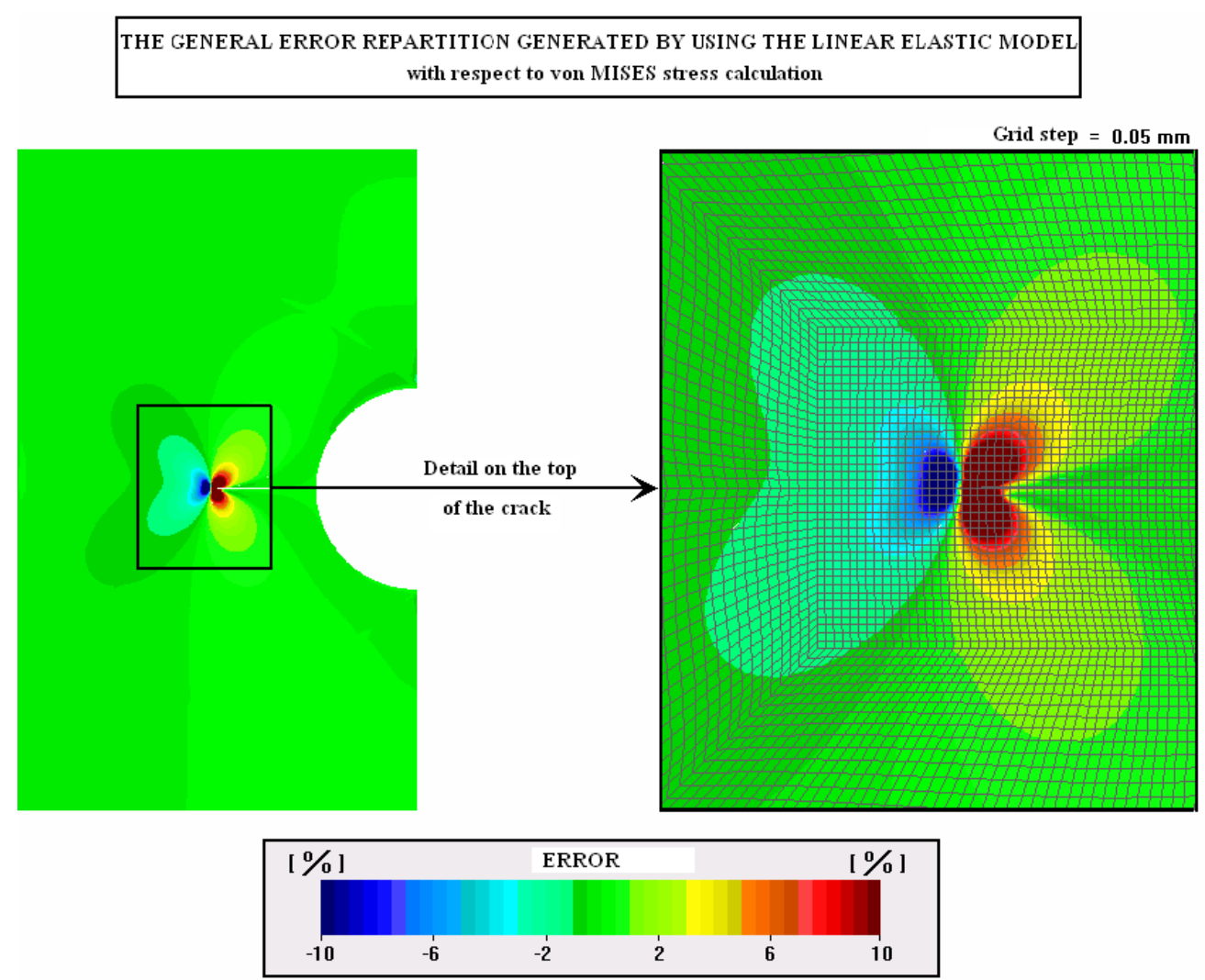

Fig. 6 The error repartition at the top of the crack

Noting that the grid step is $0.05 \mathrm{~mm}$, from the Fig. 6, it can be concluded that the dimensions of the zone I are enough small in comparation with the dimensions of the model. As the point is enough far from the top of the crack (more than $1 \mathrm{~mm}$ ) the error is sensibly atenuating.

As a first result of the comparative analysis it can be concluded that the FEM model can be significantely simplified by considering the linear elastic model. In order to demonstrate this result some exercises will be done, analysing in the same time the obtained results. According to the theoretical considerations at the chapter 2, the growth of the crack is directly connected by the values of the stress intensity factor, K. Aditionally, the adopted law that model the crack evolution, particularily the Paris law, do not take into account explicitely the stresses localised at the top of the crack for propagation speed estimation. This observation authorises to make the verification by estimating the stress intensity factor calculated for the two considered material models.

The stress intensity factors are calculated via $\mathrm{J}$ integral (this method presents some advanteges in comparaison with the displacements one).

As presented in the Fig. 4, four integration contours were considered for each model of material (knowing that the $\mathrm{J}$ integral value is independent of the contour, one contour could be enough). 
It can be observed that for the elasto-plastic model the contours are polygons (defined in points) while for linear elastic model they are circles centered on the top of the crack. In the spirit of the purposed comparation it would be desirable to choose the contours sensible similar (Fig. 4).

Analysing the values obtained for the stress intensity factors it can be noticed:

- In case of the elasto-plastic model, where the stress gradients are moderated by the plastic behaviour of the material, all the 5 values of $\mathrm{K}$ are around the average value of $276.9 \mathrm{MPa}$ $\sqrt{\mathrm{mm}}$, in a dispersion band between -0.3 and $+0.3 \mathrm{MPa} \sqrt{\mathrm{mm}}$.

- In case of linear elastic model, as a result of great gradients of stress field, all the 5 values of $\mathrm{K}$ are around the average value of 274.1 $\mathrm{MPa} \sqrt{\mathrm{mm}}$, in a dispersion band between -0.9 and $+1.7 \mathrm{MPa} \sqrt{\mathrm{mm}}$.

- Despite the errors noticed in the comparative analysis of von Mises stress field (in the very vecinity of the crack top the errors are greater than 10\%), the average values of stress intensity factors differ with about $1 \%$.

These observations authorise the model linear elastic to be used in riveted joints in a good aproximation.

A final analysis that was performed in order to validate the proposed technology considering the erors with respect to the Irwin analitical solution. The comparative results are presented in the Fig. 7. It can be easily observed that the differences are very low and the calculated error does not exceed the value of $4 \%$ at the top of the crack.

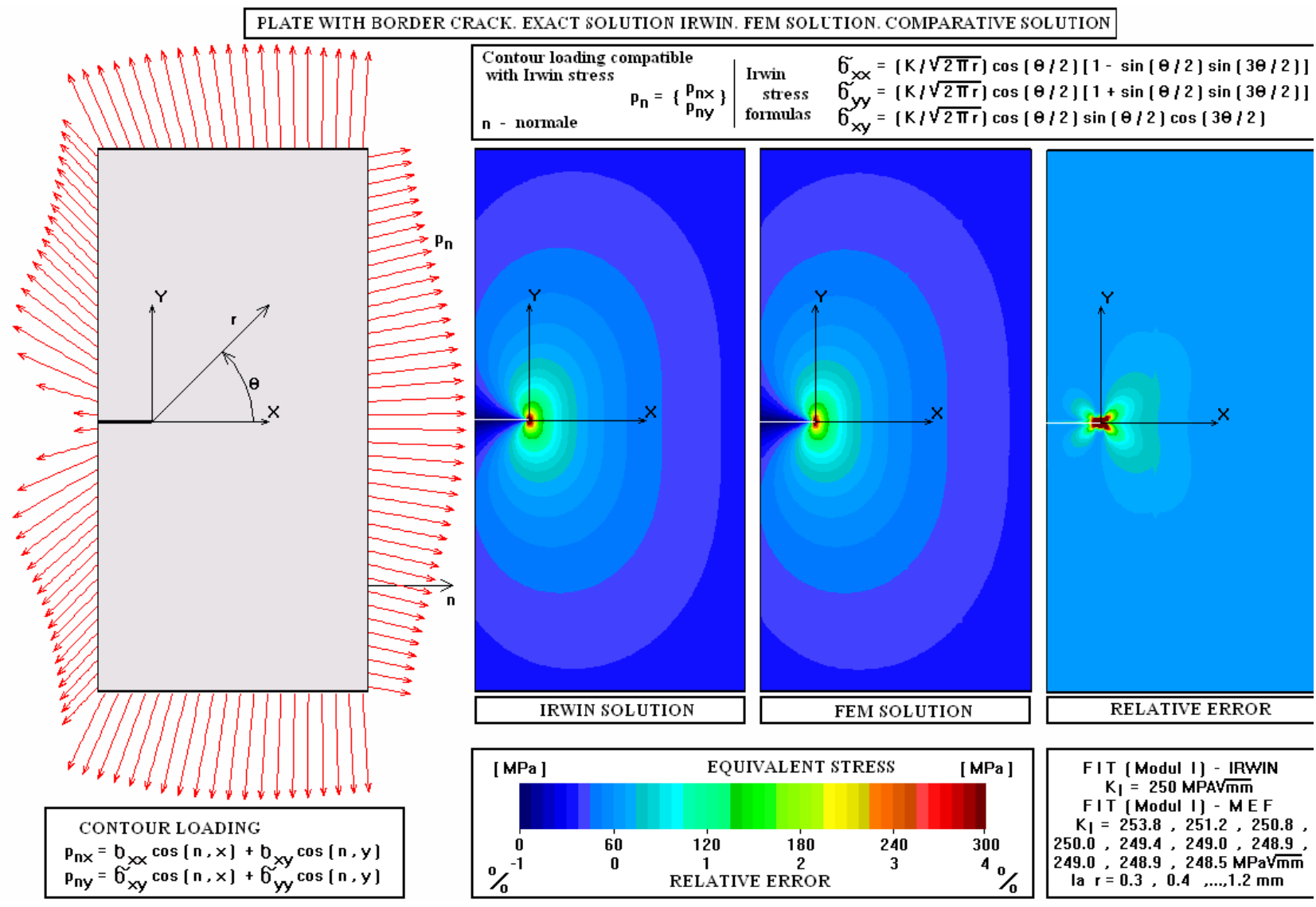

Fig. 7 Comparative analysis with respect to Irwin solution 


\section{CONCLUSIONS}

- The riveted joint model can be applied with good accuracy to estimate the durability of the structures inclusively to identify and prevent the cases of widespread fatigue damage.

- Quasi two-dimensional model for the riveted plates under the mentioned restrictions allows a short time analysis for complex structures as well as a greater number of constructive cases and the results are enough acceptable.

- The basic cell defined at the chapter 4 can be used by multiplying to realise any complex riveted joint.

- The Irwin model can be considered as a reference model to estimate the accuracy of the other models.

- As a result of parallel calculus, the mesh at the top of the crack with $0.1 \mathrm{~mm}$ geometric step was satisfactory from precision, convergence and CPU time, points of view.

\section{BIBLIOGRAPHY}

1. Apicella, A., Armentani, E., \& Citarella, R. (1998). Crack Propagation in MultiSite Damage Condition for a riveted Joint. Fisciano: Department of Mechanical Engineering, University of Salerno.

2. Apicella, A., Armentani, E., \& Citarella, R. (1997). Bidimensional Stress Analysis and SIF's Assessement of a Cracked Aeronautic Doubler-Skin Assembly by BEM and FEM. Fisciano: Department of Mechanical Engineering, University of Salerno.

3. Bruhn, E. (1965). Analisys and design of flight vehicle structures. Cincinnati, Ohio: TriState Offset Company.

4. Bucci, R. J., \& Warren, C. J. (2000). Need for New Materials in Aging Aircraft Structures. Journal of Aircraft, Vol. 37.

5. Cali, C., Citarela, R., \& Perrela, M. (1998). Multiple site damage (MSD) crack growth: numerical evaluations and experimental tests. Fisciano: Department of Mechanical Engineering, University of Salerno.

6. Edwards, P. R., \& Newman, Jr., J. C. (1990). Short-Crack Behavior in Various Aircraft Materials, AGARDS R-767. France: Neuilly-Sur-Seine.

7. Fawaz, S. A. (1997). Fatigue crack Growth in Riveted Joints. Ph. D. Thesis. Netherlands: Delft University Press.

8. Harris, C. E., Piascik, R. S., \& Newman, Jr., J. C. (1997). A practical engineering approach to predicting fatigue crack growth in riveted lap joints. Hampton: NASA Langley Research Center, Center of Excellence in Structures and Materials.

9. Ingram, J. E., Kwon, Y., \& Fawaz, S. A. (1997). 3D Finite Element Modeling of MSDcracked structural Joints. Netherlands: Delft University Press.

10. Rusmee, P. (2005, September). Fatigue Crack Growth. Retrieved 27 July 2010, from www.mech.utah.edu/ rusmeeha/lab Notes/fatigue.html 